\title{
Interventional suite and equipment management: cradle to grave
}

\begin{abstract}
The acquisition process for interventional equipment and the care that this equipment receives constitute a comprehensive quality improvement program. This program strives to (a) achieve the production of good image quality that meets clinical needs, (b) reduce radiation doses to the patient and personnel to their lowest possible levels, and (c) provide overall good patient care at reduced cost. Interventional imaging equipment is only as effective and efficient as its supporting facility. The acquisition process of interventional equipment and the development of its environment demand a clinical project leader who can effectively coordinate the efforts of the many professionals who must communicate and work effectively on this type of project. The clinical project leader needs to understand (a) clinical needs of the end users, (b) how to justify the cost of the project, (c) the technical needs of the imaging and all associated equipment, (d) building and construction limitations, (e) how to effectively read construction drawings, and (f) how to negotiate and contract the imaging equipment from the appropriate vendor. After the initial commissioning of the equipment, it must not be forgotten. The capabilities designed into the imaging device can be properly utilized only by well-trained operators and staff who were initially properly trained and receive ongoing training concerning the latest clinical techniques throughout the equipment's lifetime. A comprehensive, ongoing maintenance and repair program is paramount to reducing costly downtime of the imaging
\end{abstract}

\footnotetext{
K. J. Strauss $(\bowtie)$

Radiology Physics and Engineering,

Children's Hospital Boston,

Harvard Medical School,

300 Longwood Ave.,

Boston, MA 02115-5737, USA

e-mail: Keith.Strauss@tch.harvard.edu

Tel.: +1-617-3556285

Fax: +1-617-7300573
}

device. A planned periodic maintenance program can identify and eliminate problems with the imaging device before these problems negatively impact patient care.

Keywords Radiation dose - Interventional equipment . Maintenance performance standard .

Technical settings interventional suite

\section{Introduction}

The life of any fluoroscopic imaging device begins with someone's desire for it and ends on the day it is removed from its clinical environment. In between these cradle and grave milestones, the machine must meet clinical objectives, provide good image quality, and reduce radiation dose to both patients and personnel - the concept of ALARA. Achievement of these objectives is not automatic; a well-organized program designed to achieve comprehensive quality improvement in a cost-effective manner is required. Our children who need to be imaged with ionizing radiation depend on us to provide this level of care.

This paper outlines the steps of a comprehensive quality improvement program for fluoroscopic imaging equipment. The first step in this process identifies the clinical requirements (not to be confused with desires of the operator) of the imager. This identification assists with the second step: securing adequate funding for the project. With funding secured, one next acquires the imager by identifying the vendor of choice, negotiating the purchase, and issuing a purchase contract for the imager. Because the chosen imager can only be as effective and efficient as its supporting facility allows, one begins the fourth step of careful facility planning followed by monitoring of the progress of renovation/construction. After the unit is installed, the owner acceptance-tests the imager and trains its staff. The final step begins after commissioning of the unit and continues throughout its useful life. It involves a comprehensive program of routine testing, maintenance, repair, and record-keeping to maintain the performance of the unit. 


\section{Identification of clinical requirements}

The most important step in planning the acquisition of fluoroscopic equipment is the identification of clinical needs [1]. This is achieved by asking a series of questions of the end users of the equipment and their associates [2]. These people might be overwhelmed and confused by the equipment-acquisition process [3] or might understand many of the technical issues [4]. The imaging physicist should review product literature and technical specifications of the vendors' product line on a component-bycomponent basis to develop an understanding of each vendor's strengths and weaknesses. Discussions with all other stakeholders should allow the imaging physicist to develop an understanding of other concerns of the hospital's administration and imaging department. This broad understanding of clinical, technical, and administrative issues allows the imaging physicist to manage the process in a logical fashion and serve as an interpreter between the end users and vendor [5]. This avoids problems that arise when end users do not understand a vendor's limitations and the vendor does not understand the unique clinical needs of the end user. Participation by all the stakeholders, with effective leadership striving to create a global understanding of the entire project, allows the development of a complete imaging facility that provides quality, cost-effective patient care.

The end users of fluoroscopic equipment and their associates are a complex group of professionals, each with a unique perspective. The fluoroscopists, the clinical managers of procedures, must answer questions concerning (a) variety of patients (e.g., adult, pediatric, etc.), (b) range of clinical examinations to be performed, (c) referral patterns of patients today and in the future, (d) anticipated future patient volume, and (e) necessary equipment options. The technologists, the technical managers of ongoing cases, need to provide answers to questions concerning (a) imaging equipment options, (b) equipment operational issues, (c) associated equipment, (d) catheter, guidewire, and other supply management issues, and (e) required support spaces outside the imaging suite. The nurses, managers of the clinical needs of the individual patient, should provide advice concerning (a) required support spaces outside the imaging suite, e.g., sedation and/ or recovery beds, (b) medical gas requirements, (c) physiological monitoring needs, (d) drugs and other patient care supply issues. The anesthesiologists need to answer questions concerning (a) anesthesia equipment, (b) physiological monitoring equipment, (c) medical gas requirements, and (d) additional support spaces outside the procedure room. The hospital's Information Services (IS) group, in consultation with all of the above individuals, must address questions concerning communicationsdissemination of scheduling information, images, physiological data, and clinical reports to all clinicians inside and outside the institution. Administrators need to participate in all of the above discussions to gather the knowledge and information that will allow them to prepare a written justification of the clinical program.

\section{Justification of the project}

Well-defined clinical requirements for an imaging device developed by participation of all the stakeholders make the justification of the associated costs to senior administration of the facility more manageable. The administrator of the project must develop a comprehensive business plan that identifies all the costs associated with the project and all the projected revenues based on the best information available from all the stakeholders. The institution might find a properly qualified outside consultant, without any bias or conflict of interest, helpful in developing this analysis [6].

Both capital and operational costs along with projected revenue associated with the project must be quantified. Typical costs have been described previously [7]. In addition to direct capital and operating expenses, one must identify indirect costs such as additional services that other departments provide to patients. Revenue from patient studies by the proposed imaging device must be quantified, accounting for any anticipated changes in thirdparty payer or governmental reimbursement programs [6]. If the project replaces existing equipment with high maintenance costs, service cost savings and/or increased patient revenues resulting from the improved equipment reliability must be considered. Because the clinical requirements of the project have revealed the scope of imaging and associated equipment, the dilemma of approval of inadequate funding to complete the project properly is avoided.

If projected costs exceed projected revenues, nonrevenue advantages should be considered before funding is denied. Does the project contribute to the overall mission and goals of the institution, help attract and retain professional staff, provide prestige resulting in new patient referral patterns, minimize legal liability, or better serve the health needs of the community? Would a lease instead of a direct purchase allow the project to fit within the institution's budgetary constraints?

\section{Equipment acquisition planning}

Methods have been developed to allow the funded clinical end user, as opposed to an equipment vendor, to control the acquisition of equipment [8-15]. Typically, the buyer writes a Request for Proposal (RFP). The vendors, under a defined set of equipment requirements and buyer conditions, offer equipment that best fulfills clinical needs. The team of clinical stakeholders who identified clinical needs can objectively choose the vendor based on the vendors' responses to the RFP. A purchase order is issued to the chosen vendor that incorporates all of the purchase conditions of the RFP into the contract of sale.

RFPs for imaging equipment should contain (a) explicit general purchase conditions, (b) generic equipment specifications and requirements, (c) acceptance-testing methods, and (d) expected performance levels. The general purchase conditions spell out proposed responsibilities of the selected vendor and buyer to be incorporated into the 
final purchase contract. The buyer's purchasing agent, legal counsel, department administrator, and/or imaging physicist may help prepare the buyer's terms within the RFP. Table 1 lists some of the typical business/legal aspects

Table 1 General purchase conditions

1. Financial terms

a. Price

b. Shipping and rigging costs paid by vendor

2. Shipment and risk of loss

a. FOB hospital loading dock

b. Shipping and rigging costs paid by vendor

3. Site preparation responsibilities

a. Installation drawing deadline from vendor

b. Site preparation responsibility of buyer

c. Prestaging of equipment

4. Delivery issues
a. Delivery date
b. Documentation delivered with equipment
c. Loading dock restrictions
d. Local storage obligations of vendor

5. Late-breaking field modifications

6. Vendor's obligation to announce new models prior to delivery

7. Installation issues

a. Vendor responsible for all installation costs including union and rigging

b. Completion date

c. Buyer's responsibilities with respect to site preparation

8. Vendor-supplied training

a. Clinical users

i. On site

ii. Off site; tuition, room, and board

b. In-house service engineers

i. On site

ii. Off site; tuition, room, and board

9. Acceptance of equipment

a. Acceptance testing procedures

b. Transfer of title to hardware

c. Vendor's obligations in the event of nonacceptance by buyer

10. Equipment safety

11. Field service notes

12. Performance warranties

a. Scope

b. Guaranteed uptime and remedies for failure

c. Periodic maintenance checks during warranty

d. Vendor response during warranty

13. Infringement indemnification/remedies

14. Acts and omissions indemnification

15. Termination/remedies

16. Insurance carried by vendor

17. Confidentiality/nondisclosure

18. Assignment of contract

19. Governmental access to books and records

20. Dispute resolution

21. HIPAA compliance by vendor
Table 1 (continued)

\section{Service support}

a. Scope

i. Hardware

ii. Software

b. Buyer's use of service documentation (in-house agreement)

c. Hours of service

i. Phone support

ii. On-site support

iii. Technical support hotline

d. Buyer's responsibilities

e. Excluded services

f. Financial terms

g. Warrantie

h. Acts and omissions indemnification

i. Termination/remedies

j. Insurance

k. Confidentiality/nondisclosure

1. Assignment

m. Governmental access to books and records

of the purchase. A vendor's rejection of proposed terms in the RFP identifies potential disputes that could delay the timely signing of a contract. If the buyer's business terms are absent in the RFP, the standard purchase conditions of the vendor's quotation apply. This situation seldom favors the buyer.

The generic equipment specifications in the RFP allow the buyer to communicate to all vendors the equipment that should be offered from their product line to best address the buyer's clinical needs. The generic specifications begin with a statement of the clinical requirements that includes a listing of anticipated clinical procedures, description of the patient mix, anticipated patient volumes, and any identified special clinical constraints [12]. This is followed with a generic description of each component of the fluoroscopic system. The component specification needs enough detail to define clinical needs but must remain generic enough to encourage competitive bidding. RFP responses from each vendor allow the buyer to make direct comparisons of many different performance parameters.

\section{Facility planning and construction}

While the imaging equipment is being selected, facility planning issues, discussed in more detail elsewhere $[7,16$, 17], must be addressed. Fluoroscopic equipment must be housed in a controlled environment with proper support space for patients and staff to function properly. If facility planning is not completed properly, the performance of the imaging device and its operators will be impaired at the expense of achieving ALARA patient and personnel radiation doses. If end users have the opportunity to provide thoughtful input and answers to the appropriate clinical concerns, the end product will be much more 
satisfactory, effective, and efficient. Most end users can quickly identify deficiencies in the constructed facilitythe time when change orders are most costly in terms of time and money. The challenge is to identify the appropriate questions to be answered during the planning process so costly construction errors can be avoided.

Effective communication between the clinical end users and building professionals based on a mutual understanding of each other's working environment is important. The imaging physicist can foster this communication by functioning as interpreter between these two major groups of professionals, illustrated in Fig. 1. The imaging physicist should have a basic knowledge of the clinical needs of the end users and the functional environment that is required by the purchased equipment. He/she should be proficient at reading construction drawings and identifying proposed issues on the plans that need further discussion. The imaging physicist should closely monitor progress on the construction site after the plans are finalized. Identifying problems during construction that were missed on paper might not save change-order costs but might minimize delays in opening the facility. This monitoring by the buyer continues until acceptance-testing of the equipment is complete.

\section{Site planning guides from the vendor}

Site planning guides or generic installation drawings for the selected vendor's equipment provide technical information such as weights of equipment components, heat generation of the components, and other demands the imaging equipment places on its environment. This information is submitted to building engineers who work in association with the architect to design the functional aspects of the imaging suite.

\section{FACILITY PLANNING}

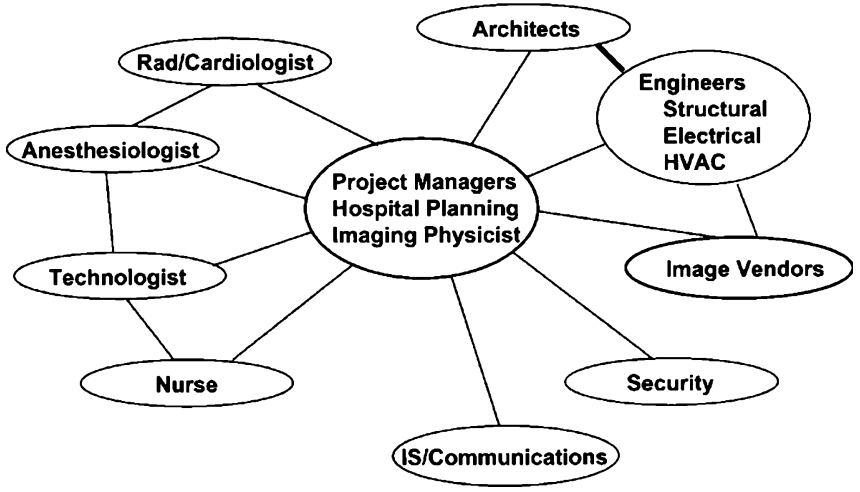

Fig. 1 An illustration of the variety of professional individuals who must communicate effectively with one another to ensure a successful creation of the environment required to allow a stateof-the-art fluoroscopy imaging unit to reach its designed potential

\section{Adjacencies}

If the facility is new, adjacencies to other clinical services in the building must be considered. In addition to properly locating the imaging suite with respect to other important clinical services, the final location must be accessible to available loading docks, pathways, and elevators to allow delivery of potentially bulky equipment when the building is new and throughout the building's lifespan. Constraints of the building's design, e.g., floor loading limitations, floor deck clearances, elevator sizes, etc., and the overall space requirements of the imaging suite might restrict its potential locations.

\section{Space program}

The end users with the help of the architect must develop a space program that lists each space in the imaging suite and the items or attributes that will be housed in each space. Listing the contents of a room help to understand its function and determine its required square footage. Table 2 is a listing of some of the more common items that need to be considered for inclusion in imaging rooms and their support spaces. Pediatric imaging rooms might need to be supported by sedation/recovery areas with patient toilets and a nurse's station. Patient changing rooms and lockers are necessary. A waiting room for members of the patient's family, a reception desk and a semiprivate registration desk that is HIPAA-compliant might be necessary. Routine patient examination rooms and consultation rooms might be necessary. Ample, properly located storage space for all necessary supplies is imperative. This typically involves a central supply room with more limited storage within each procedure room. Security of all stored items must be carefully addressed. A soiled utility room for materials contaminated by patient fluid is required. A central computer room might be necessary for a local archive associated with the institutional PACS. Proper workspaces are needed for nurse practitioners, anesthesiologists, fellows, administrative assistants, technologists, and other clinical staff. If brachytherapy radioactive sources will be used in the suite, space is needed to properly handle and store them. A reading room might be required to allow interpretation of the images. Office space is needed for staff within or adjacent to the clinical working area.

\section{Floor plans and other drawings}

After the location and size of the space program is complete, adjacencies within the imaging suite need to be planned. The biggest blocks of space, i.e., the imaging rooms, are placed first. Soft spaces with no clear-cut adjacencies are used to fill the gaps between the large blocks. These soft spaces can be converted in the future if new technology requires larger imaging rooms. Figures 2 and 3 demonstrate this principle. 
After intradepartmental spaces are placed, the details of each individual space within the suite must be planned [16, 17]. To verify the presence of all the necessary attributes in each room (subset of all items listed in Table 2), three sets of drawings need to be reviewed. These include scaled floor plans, reflected ceiling plans, electrical drawings, and elevation drawings (Figs. 3, 4, 5 and 6, respectively).

Table 2 Potential attributes within each room. See text for a description of many of the functional systems
1. Electrical power
a. $440-\mathrm{V}$ circuits
b. 220-V circuits
c. $110-\mathrm{V}$ normal outlets
2. Electrical pathways
a. Wall phone
b. Desk phone
c. Data connections
d. Intercom

d. $110-\mathrm{V}$ emergency outlets

3. Communication connections

4. Heating, ventilation, air conditioning (HVAC)

a. Thermostat present

5. Lighting
a. Fluorescent ceiling lights
b. Overhead spot lights on rheostats
c. Over-counter task lights
d. Wall washing lights on rheostats
e. Corridor lighting
f. Interface circuitry to imaging equipment
g. Storage of sterile supplies
h. Patient examination lights

6. Floor treatment
a. Tile
b. Seamless vinyl
c. Carpet

7. Wall treatment
a. Paint
b. Wallpaper border and paint
c. Wallpaper
d. Protective devices
i. Chair rail
ii. Stainless steel corner guards

8. Doors
a. Automatic openers/hold open
b. Stainless steel corner guards
c. Stainless steel kick plates
d. Locks

9. Mechanical supports

a. Universal ceiling grid

b. Wall blocking

10. Medical gases

a. Correct quantities

i. Oxygen

ii. Air

iii. Vacuum

iv. Nitrous
Table 2 (continued)
11. Storage
a. Cupboards
b. Drawers
c. File cabinets
d. Locks
e. Open book shelves
f. Protective aprons
g. Hanging catheters and guidewires
h. Compressed shelving
i. Drugs
12. Radiation shielding
13. Plumbing
a. Sink
b. Toilet
c. Shower
14. Furniture
a. Desk
b. Desk chair
c. Side chair
d. Waiting room chairs
e. Examination table
15. Auxiliary equipment
a. Clocks
b. Desktop computers
c. Keyboard trays
d. Viewboxes
e. PACs workstations
f. Lockers
g. Mobile lead shields
i. X-rays
ii. Brachytherapy radioactive materials
h. Protective aprons
i. Power injector
j. Crash carts
k. Drug safe and dispenser
1. Physiological monitoring equipment
m. Patient stretchers

Carefully checking the attribute checklist in Table 2 for each space and checking the location of each attribute on each of the above drawings is a tedious task. However, these drawings become the contract that determines what is owned and where it will be installed in the finished facility. Information on the construction drawings defines the scope of work included in the contractors' competitive bids. The buyer does not pay a penalty for any corrections made to the architectural drawings prior to bidding. After that time, any changes to the drawings require a change order that comes at a premium price. The credits for work on the drawings not completed are always smaller while the costs for the additional work are always higher than competitively priced work in the original contract. Construction drawings without errors result in the most functional constructed facility at the least cost. 


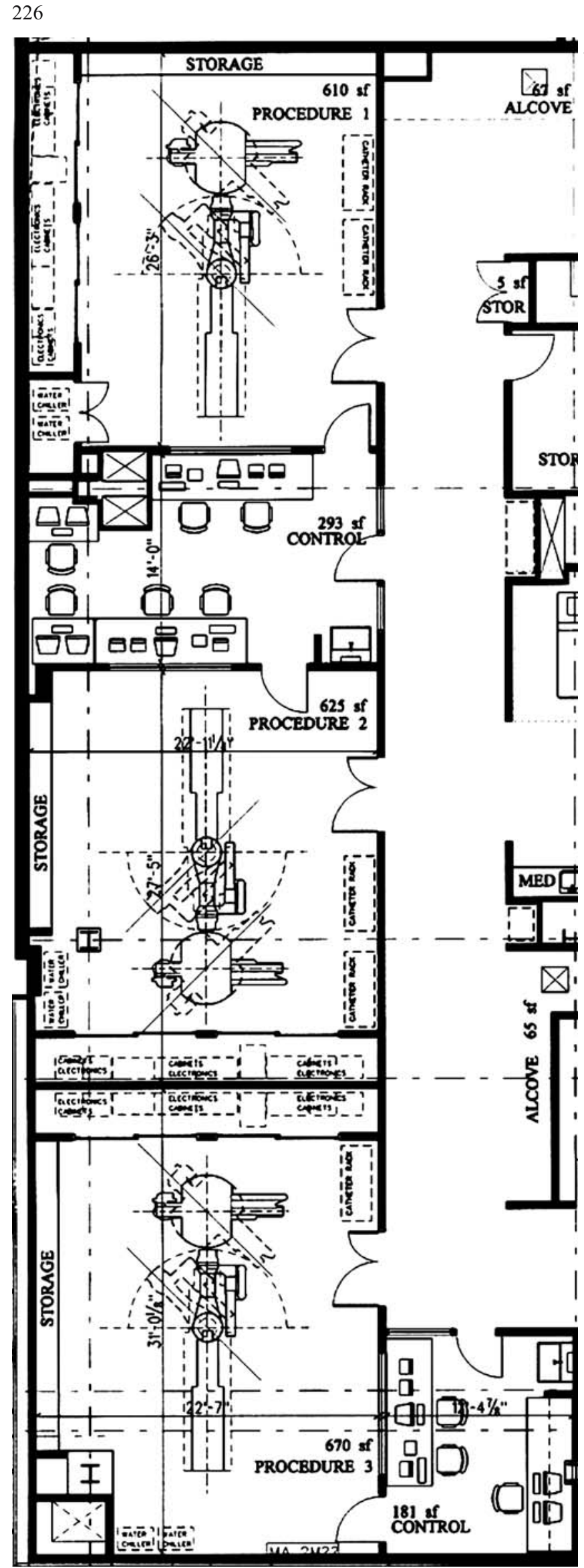

Fig. 2 A partial floor plan of a fluoroscopic suite illustrates a nonstrategic layout of three procedure rooms and their control rooms that are landlocked and cannot grow to accommodate future equipment needs. Reprinted with permission of Medical Physics Publishing [7]

\section{Functional systems}

\section{Electrical power}

A dedicated electrical power circuit, a circuit with no other heavy electrical loads, ensures peak performance of the imaging system. Other large electrical motors associated with elevators and air-handling systems should not be allowed over the years to migrate to the dedicated X-ray power circuits. This is achieved by specifying all X-ray equipment and its power circuits at $440 \mathrm{~V}$, a power source useless to facility electric loads designed for $480 \mathrm{~V}$.

\section{Electrical pathways}

Pathways must be provided for electrical cables that carry either power or signals between the numerous components of the fluoroscopic unit. A universal design of these pathways avoids their replacement each time the equipment is replaced. Because newer equipment designs reduce the number of bulky interconnecting cables, designing extra capacity in the original pathways for future needs is probably not necessary. In cases where electrical cables must travel beneath the floor, pipes with large sweeping bends as those illustrated in Fig. 7 [18] allow cables to be pulled from within the procedure room. These pipes should extend an inch above the floor deck to prevent fluids on the deck from running into the pipe. This design provides a more maintenance-free solution than an embedded floor trough with removable covers flush with the floor. In the latter case, loss of the watertight seal between the covers and trough causes caustic floor strippers to enter the trough. The strippers damage the insulation on the electrical cables, leading to erratic equipment failure caused by electrical shorts.

\section{Heating, ventilation, air conditioning (HVAC)}

The HVAC system required for an imaging unit might be an auxiliary unit to the general building HVAC service. The heat gain during the operation of the imaging equipment is large. The temperature and the humidity in the procedure and equipment room need to be controlled. Sterility requirements might eliminate the less-expensive option of a recycled air supply. This greatly increases the required capacity of the HVAC system. A supply of chilled water might be required by the HVAC system. HVAC costs for imaging equipment can significantly impact the overall cost of the project. These costs should be quantified and included in capital cost projections during the project justification step prior to approval of the project. 
Fig. 3 Rotating room C 90

degrees and relocating its con-

trol room creates a more strategic layout than Fig. 2. This procedure room can be lengthened or shortened (at the expense of only soft space, a supply store room) as dictated by future equipment. Reprinted with permission of Medical Physics Publishing [7]

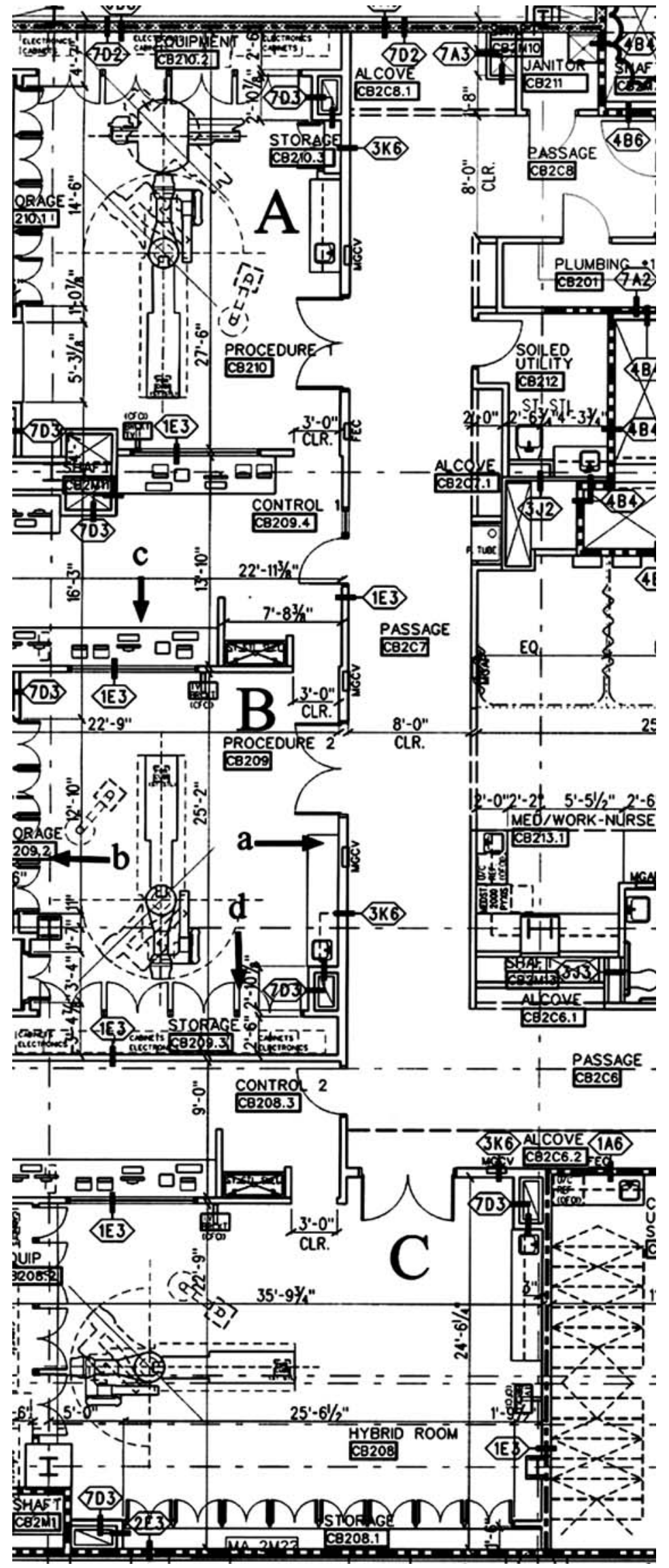


Fig. 4 The reflected ceiling plan of a room locates each object mounted on the finished ceiling when viewed from the floor looking up. Locations of fluorescent lights, incandescent lights, track lights, ducts, sprinkler heads, unistrut, and other ceiling-mounted devices are indicated. Reprinted with permission of Medical Physics Publishing [7]

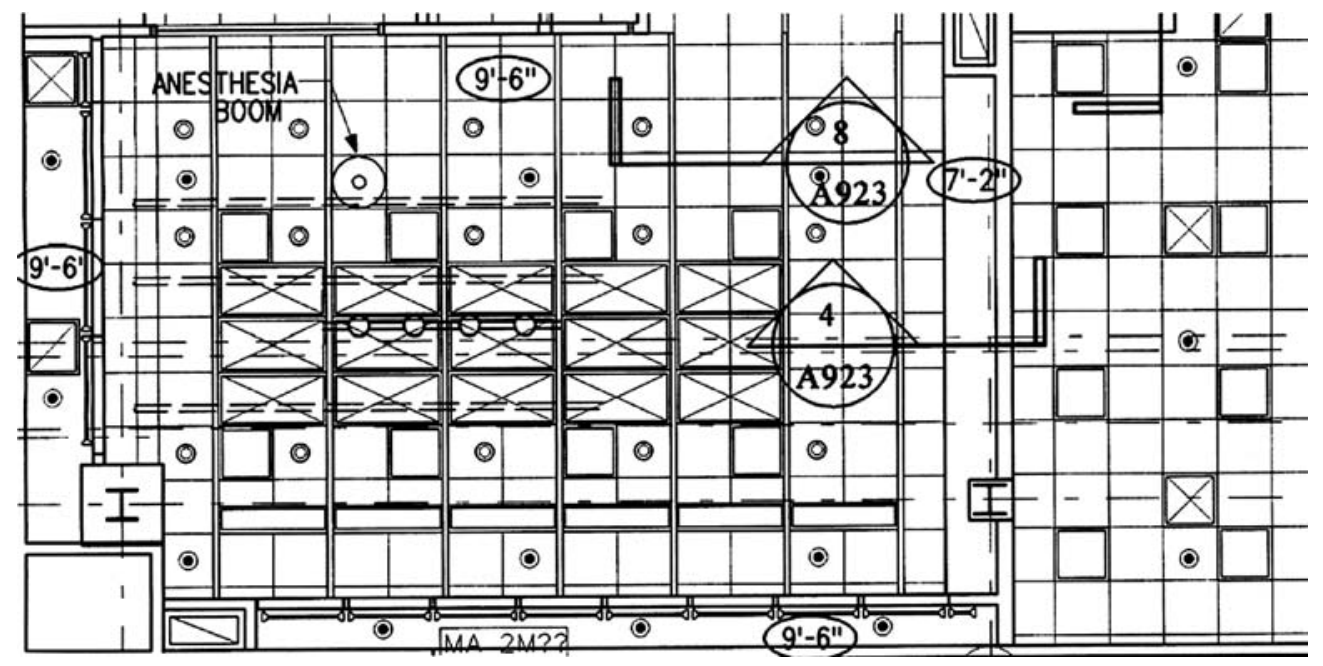

Lighting

All rooms in the imaging suite need overhead fluorescent lights with standard switches to provide general light levels for cleaning of the facility. Overhead fluorescent lights at intervals in corridors and hallways must be avoided. This type of lighting generates alternating light intensities shining down on patients as they are transported on stretchers. This can wake up the sedated patient on their way to the imaging room or cause patients in the process of regaining consciousness after the procedure to go into a rage. Cove lighting continuously placed along the corridor to wash the corridor wall in light avoids these undesirable effects.

Adjustable intensities of light at different locations in the imaging and control rooms are necessary in addition to the fluorescent lights. At least one operating-room-quality light source that can be directed to different locations of the patient's body is needed. Dimmable, incandescent spotlights should be provided to serve the different lighting needs of each work area in the rooms, e.g., sterile supply table, anesthesia work station, imaging workstation in control room, etc. Under-cabinet lights that illuminate the counters of casework provide both task-oriented light at the counter and low levels of indirect light. Typically, an interface between the imaging equipment and work zone lights automatically lowers the light levels in the room during fluoroscopy to allow proper viewing of the fluoroscopic image. A means to deactivate this fluoroscopy/light interface is helpful for operators who find it distracting to change light levels during the procedure.

\section{Mechanical supports}

Required mechanical supports are dictated by the imaging equipment design. The floor deck must be capable of supporting the point loads of the installed equipment. Floor-mounted equipment must be secured either by anchored bolts in the floor or possibly a through-bolt design with a plate on the underside of the floor slab. In the latter case, the plate and through-bolt must be secured to
Fig. 5 Electrical drawings illustrate the presence of standard electrical duplex outlets, emergency power electrical duplex outlets, and communication drops for phone and data hookups. Reprinted with permission of Medical Physics Publishing [7]

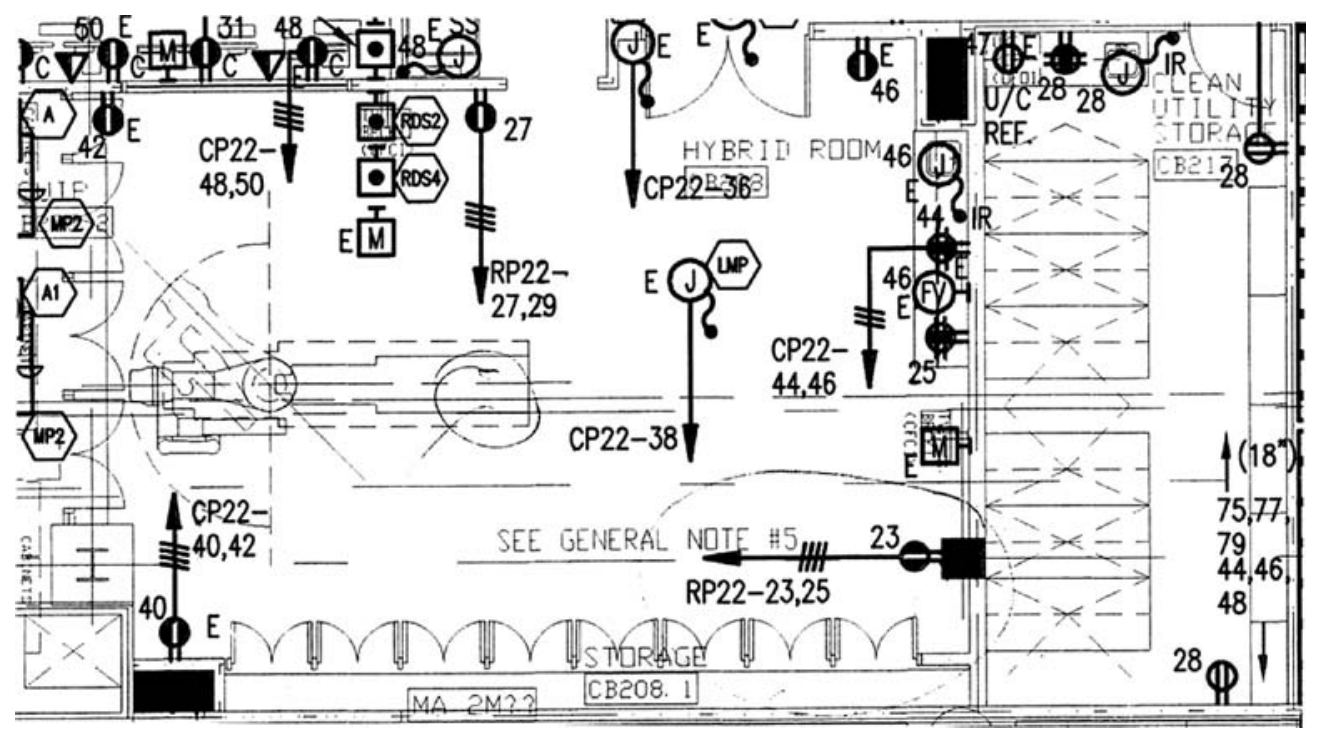




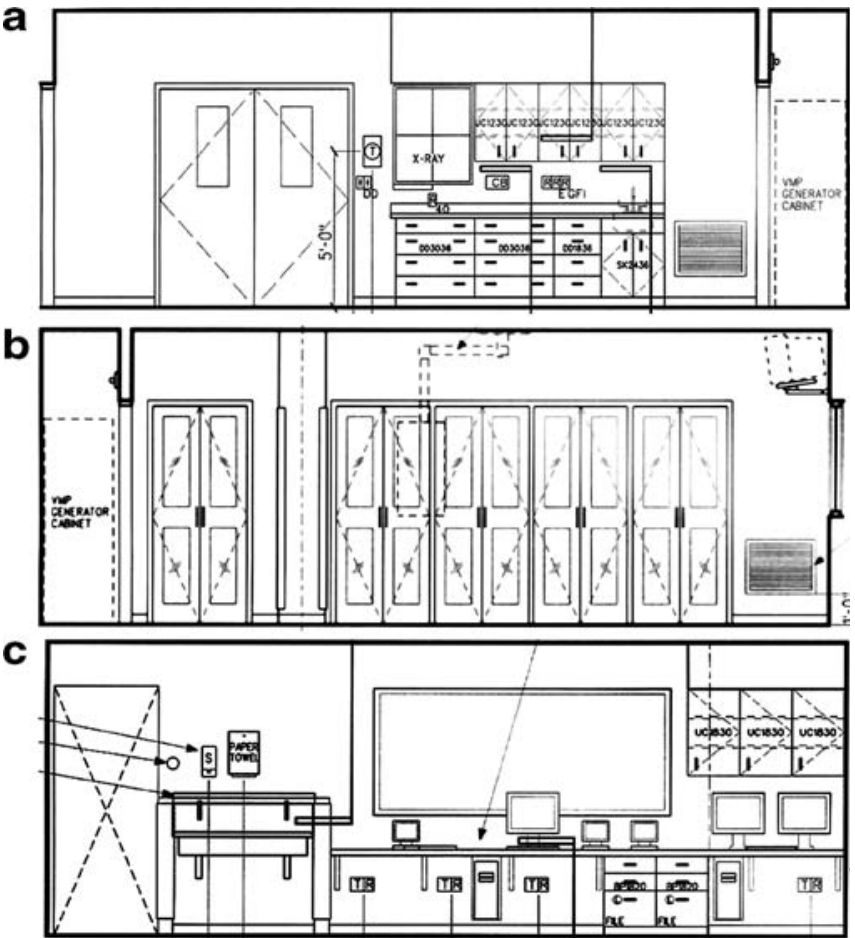

Fig. 6 Elevation drawings are views of individual walls viewed from the center of the room. Elevation drawings indicate where objects will be mounted on the wall, e.g., doors, casework, vents, light fixtures, light switches, thermostats, view windows, view boxes, etc. a Elevation of right wall of room "B" in Fig. 3. b Elevation of left wall of room "B" in Fig. 3. c Elevation of control room wall (from within the control room) to room "B" in Fig. 3. Reprinted with permission of Medical Physics Publishing [7]

the slab below to prevent injury to occupants below the procedure room from falling bolts or plates when the equipment in the above imaging room is decommissioned and removed.

A universal grid typically constructed from unistrut steel and attached directly to the concrete ceiling slab above the imaging room supports ceiling-mounted equipment. If the original grid extends over the majority of the surface area of the ceiling and can support significant loads, it might not require changes when imaging equipment is changed, which saves long-term renovation costs. Imaging equipment rails are attached directly to the unistrut grid to allow suspended equipment to be moved linearly across the room. The imaging equipment rails are typically parallel to the longitudinal axis of the patient table, as illustrated in Fig. 8. Display monitors for the fluoroscopic images are typically suspended from ceiling rails. Auxiliary equipment, e.g., power injector heads, mobile radiation shields, physiological monitors, etc., can also be suspended from the universal grid. If an imaging plane and patient table are suspended from the universal grid, the total suspended weight increases substantially. Care must be exercised in securely attaching the steel grid to the concrete ceiling deck, as illustrated in Fig. 9.
Medical gases

Medical gases must be provided in the procedure room, in any sedation rooms, in intubation areas, at recovery bed stations, and possibly in alcoves in the hallways of the imaging suite where patients will be temporarily held. The variety of gases required in each location should be determined in consultation with the anesthesiologists and nurses. Some of these locations, e.g., temporary holding areas, recovery beds, etc., require only one supply each of oxygen, air, and vacuum. Intubation areas and the procedure room typically require at least two oxygen supplies and two vacuum latches in addition to the air supply and a supply of nitrous gases. All the support areas requiring medical gases are served well by standard wall latches and hardware. Care is required in locating gas outlets in the imaging room. The gases must be reasonably located relative to the patient and anesthesia machine but out of the way of the fluoroscope and its operator.

\section{Imaging equipment closets}

Shallow imaging equipment closets along one wall of the procedure room designed to house the numerous electronic rack cabinets of the fluoroscopic equipment provide a number of advantages. These closets, provided with their own HVAC system, allow the temperature and humidity of the equipment space to be different from those of the procedure room, improving the comfort of the patient and staff. Because the equipment is concealed in the closet, the electrical troughs and/or pipes coming down from the ceiling or up from the floor can be surface-mounted without regard to appearance, as illustrated in Fig. 10. This reduces construction and renovation costs over the life of the room. If multiple 4-foot swinging doors are installed to allow open access to the rack cabinets during service of the equipment, as illustrated in Fig. 11, the closet depth might be limited to as little as 3 feet to save floor space. If the imaging equipment does not require the entire space within

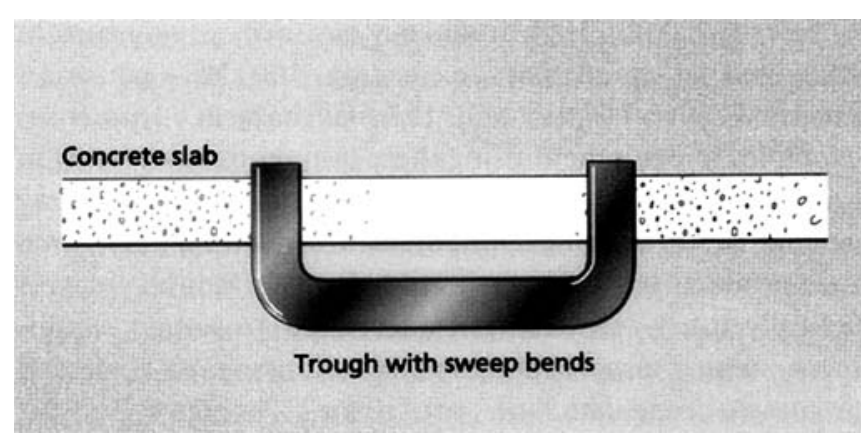

Fig. 7 Floor trough design allows all cable installation from inside the procedure room, prevents fluid from entering the trough, and eliminates the unsightly, dirt-catching floor discontinuities created by removable covers flush with floor surface. Reprinted with permission of Blackwell Science [18] 
Fig. 8 The reflected ceiling plan of a procedure room illustrates the parallel rows of steel support rails oriented at right angles to the longitudinal axis of the patient table over the majority of the surface area of the ceiling. This design provides a universal support structure for a variety of ceiling-mounted equipment, provided the grid of steel is designed to support significant weight loads. Reprinted with permission of Medical Physics Publishing [7]

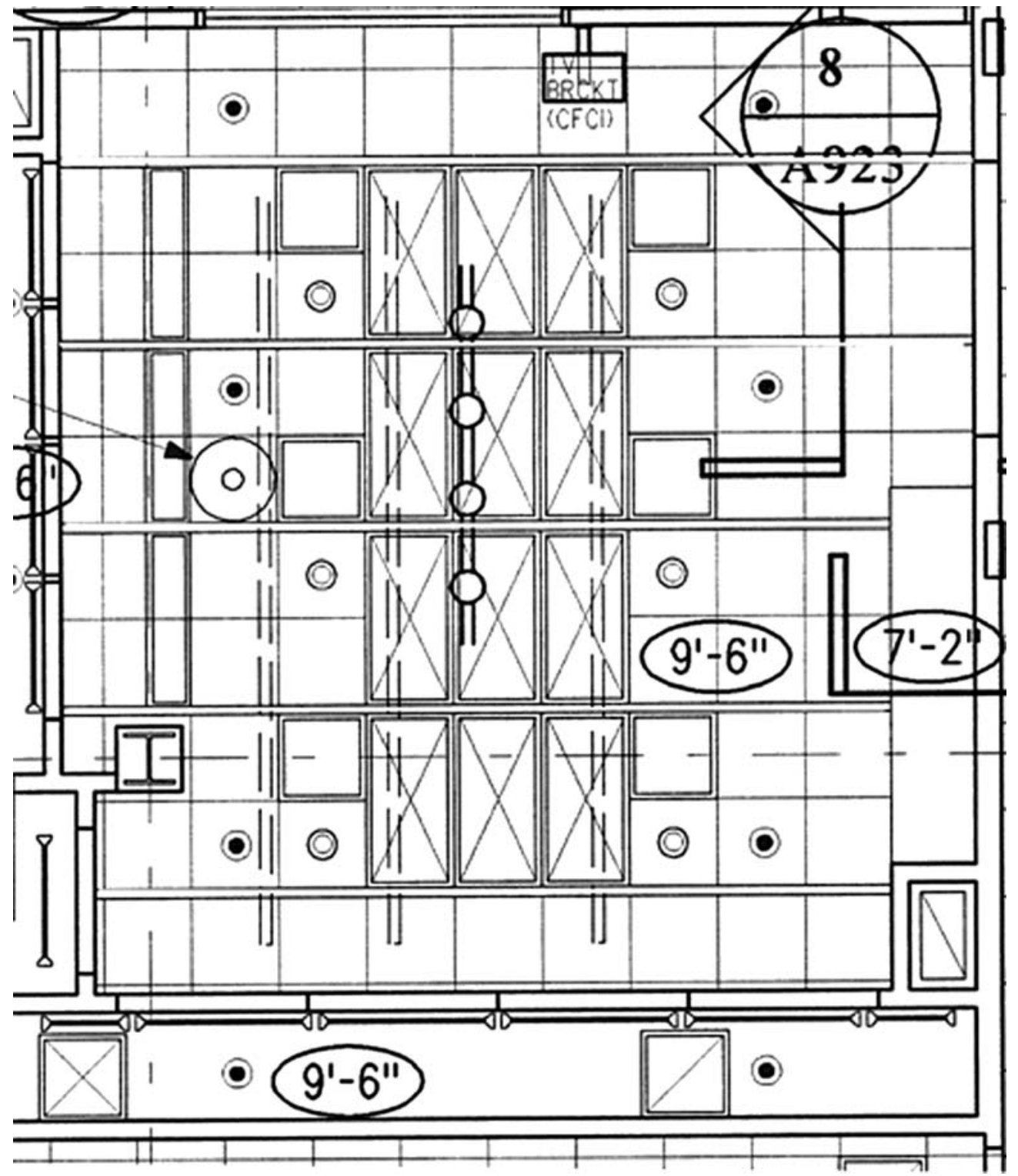

the closet, shelves can be mounted on the back wall of the empty sections to provide additional storage for supplies or for rolling bulky equipment.

\section{Storage issues}

A comprehensive storage system for the variety of goods and supplies in the imaging suite is not trivial. The suite should contain a centralized storage area with an electronic inventory system of all stocked items. Adequate space must be provided within each imaging room for the most frequently used supplies. Provision must be made to provide adequate security for drugs and other supply items that require a double-locking system.

\section{Radiation protection}

The barriers of the fluoroscopic room must reduce stray radiation levels outside the room to levels below the limits set by the state radiation control group. Typically, $0.79 \mathrm{~mm}$ to $2.37 \mathrm{~mm}(1 / 32$ in to $3 / 32$ in) of lead added to the barriers of the room provides adequate attenuation. Conventional construction of the barrier, workload of the room, distance of the barrier from the patient, and level of occupancy beyond the barrier affect the actual lead thickness for each barrier [19]. If brachytherapy with gamma-ray emitting radioisotopes is planned for the room, more shielding is required either in the stationary barriers or by mobile shields strategically placed near the patient. Prior to first clinical use of the procedure room, the imaging physicist must survey any permanently installed shielding in stationary barriers $[20,21]$. 

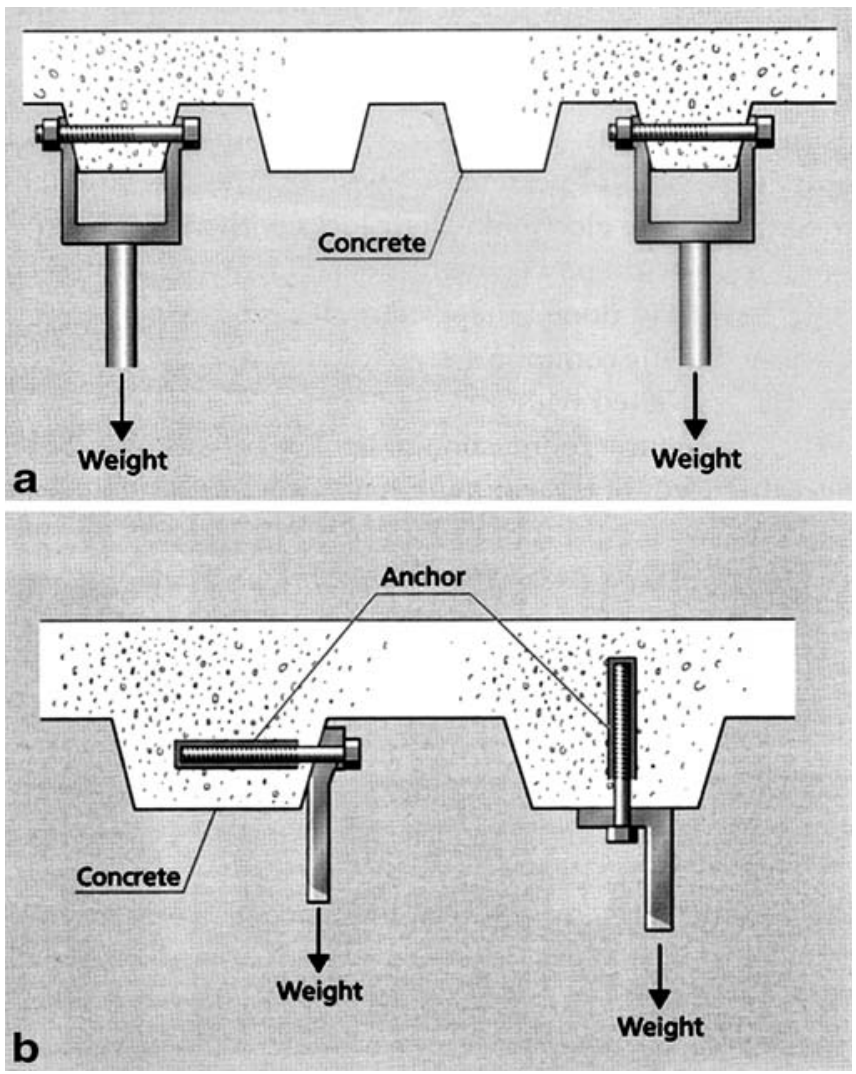

Fig. 9 Illustrates the preferred bolt-through scheme (a). If anchors must be used (b), the long axis of the bolt should be at right angles to the direction of force of gravity as shown on the left as opposed to parallel as shown on the right. Reprinted with permission of Blackwell Science [18]

\section{Information systems}

Many communication devices interfaced to the hospital network are needed within the fluoroscopic suite. Locations of phone and data drops must appear on the floor plan and elevation drawings. Appropriate interfaces between the imaging equipment and PACS or other information devices must be configured to ensure patient scheduling, management of images and reports, and billing.

\section{Wall and door protection}

Patients on stretchers and other equipment on wheels frequently collide with walls and other barriers within the suite. Chair rails in the corridors, procedure room, sedation/ recovery room, etc., prevent wall damage from collisions. Stainless steel corner guards on exposed corners prevent damage at these locations. Doors benefit from stainless steel kick plates and corner guards. Door openers that hold the door open long enough to allow a patient stretcher to pass by also prevent collisions.

\section{Acceptance testing}

Acceptance testing when the equipment is new establishes a foundation for fluoroscopic equipment quality improvement. Properly performed acceptance testing allows the (a) elimination of installation errors, (b) elimination of substandard components, (c) verification of compliance with federal, state, and local regulations, (d) verification of negotiated performance specifications in the RFP, and (e) documentation of baseline data for the equipment prior to first clinical use. The baseline performance data establish ideal performance goals for the imaging device for comparison with routine performance data collected throughout the lifetime of the equipment.

The general purchase conditions in the RFP submitted to vendors should stipulate that the fluoroscopic equipment would be acceptance-tested. The measured performance levels must achieve the negotiated performance levels before first clinical use. The imaging physicist proposes the test methods and the expected performance levels in the RFP. Each performance parameter must be measurable in the field with available test equipment. The expected performance level must be achievable with properly installed, quality fluoroscopic equipment. During the competitive bidding process each vendor can take exception in writing to a proposed test method and its expected performance level provided the vendor suggests an alternative expected performance level or test method with justification for the objection. The imaging physicist and chosen vendor now have a basis for negotiating a final performance level and test method. Vendors object strongly to performance specifications that are not clinically relevant [22-26].

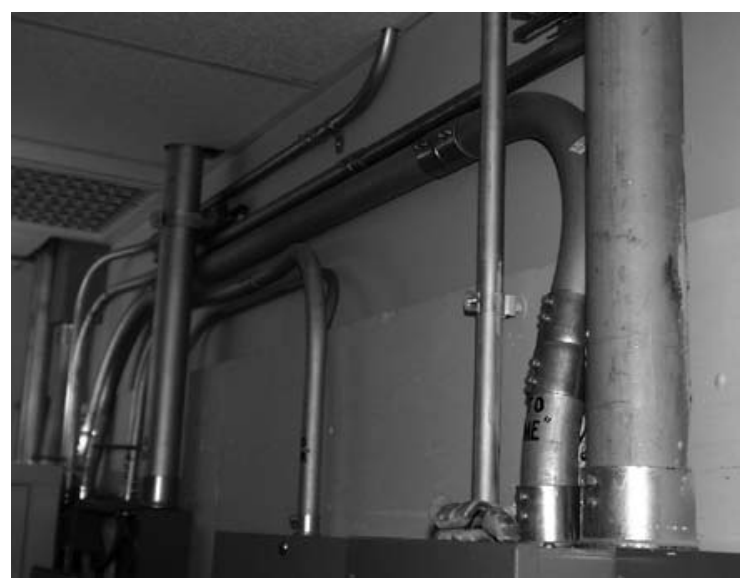

Fig. 10 If rack cabinets are concealed in equipment closets, the electrical troughs and/or pipes coming down from the ceiling or up from the floor can be surface-mounted on the back wall without concern about their appearance. This can save new and renovation costs throughout the lifetime of the procedure room. Reprinted with permission of Medical Physics Publishing [7] 
Fig. 11 Partial floor plan of an interventional procedure room. Multiple 3-foot-wide swinging doors are installed on 3-footdeep equipment closets to allow open access to the rack cabinets and equipment during service. Space not used in the closet for imaging equipment is used for storage of supplies and rolling bulky equipment. Reprinted with permission of Medical Physics Publishing [7]

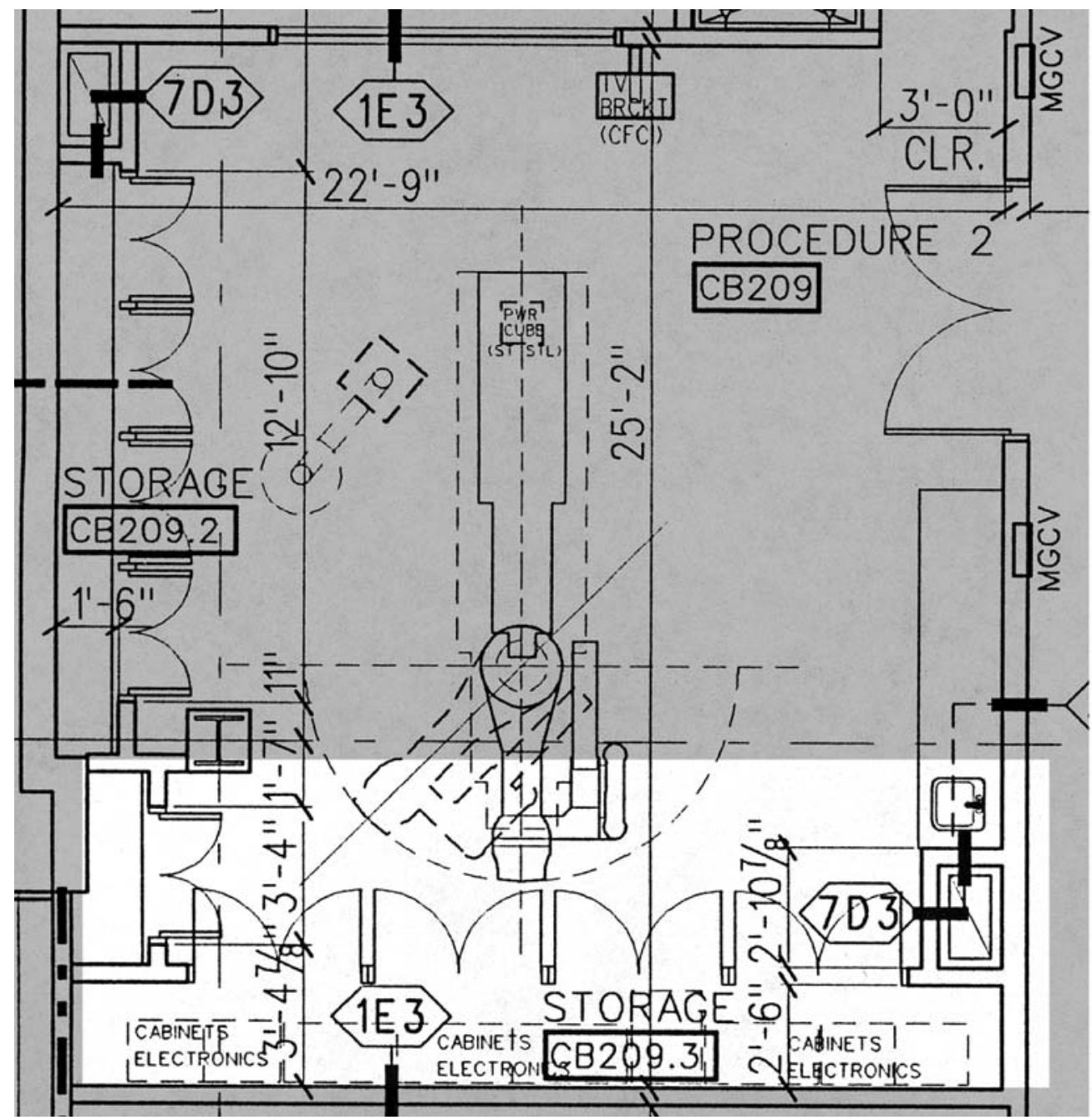

\section{Test equipment and protocols}

The imaging physicist must understand the limitations imposed by his/her test equipment and the definition of the performance parameter to be measured before reasonable performance levels for acceptance testing can be established. The test equipment chosen and its proper use have a large impact on the measured performance level of the fluoroscopic equipment. For example, invasive test methods of the X-ray generator's performance have been described in detail by others [27-41]. These methods provide the most complete analysis of the generator's performance. If care is used, noninvasive test equipment that provides high voltage waveforms can be substituted for invasive testing. However, the imaging physicist must thoroughly understand the potential limitations of noninvasive testing.

Noninvasive $\mathrm{kVp}$ meters with only a numeric display of the high voltage should be avoided. A numeric display of high voltage without a display of the high voltage waveform can be misleading. Without the display of the waveform's shape, the performance deficiencies of the generators depicted in Fig. 12 [41] would probably have been missed.
The operator of the noninvasive test equipment must correct the displayed $\mathrm{kVp}$ for systematic errors described in the operator's manual for the test device. The measured high voltage can be influenced by the degree of beam filtration, the total delivered exposure, or instantaneous exposure rate. These devices might not detect turn-on spikes at the beginning of the high-voltage waveform. The test device might generate artifacts in the displayed $\mathrm{kVp}$ waveform if the rise time of the detected signal exceeds a specified threshold. Because these devices estimate the high voltage, they must be calibrated against a known standard [41]. Finally, the test protocol must recognize and account for any manufacturer's unique, published definition of the performance parameter resulting from the design of the imaging device.

\section{Reasonable performance levels}

A discussion of reasonable performance levels for each performance parameter of a fluoroscope is beyond the scope of this paper but has been published [7]. These performance listings are the maximum errors expected from the performance of the fluoroscopic equipment. The 

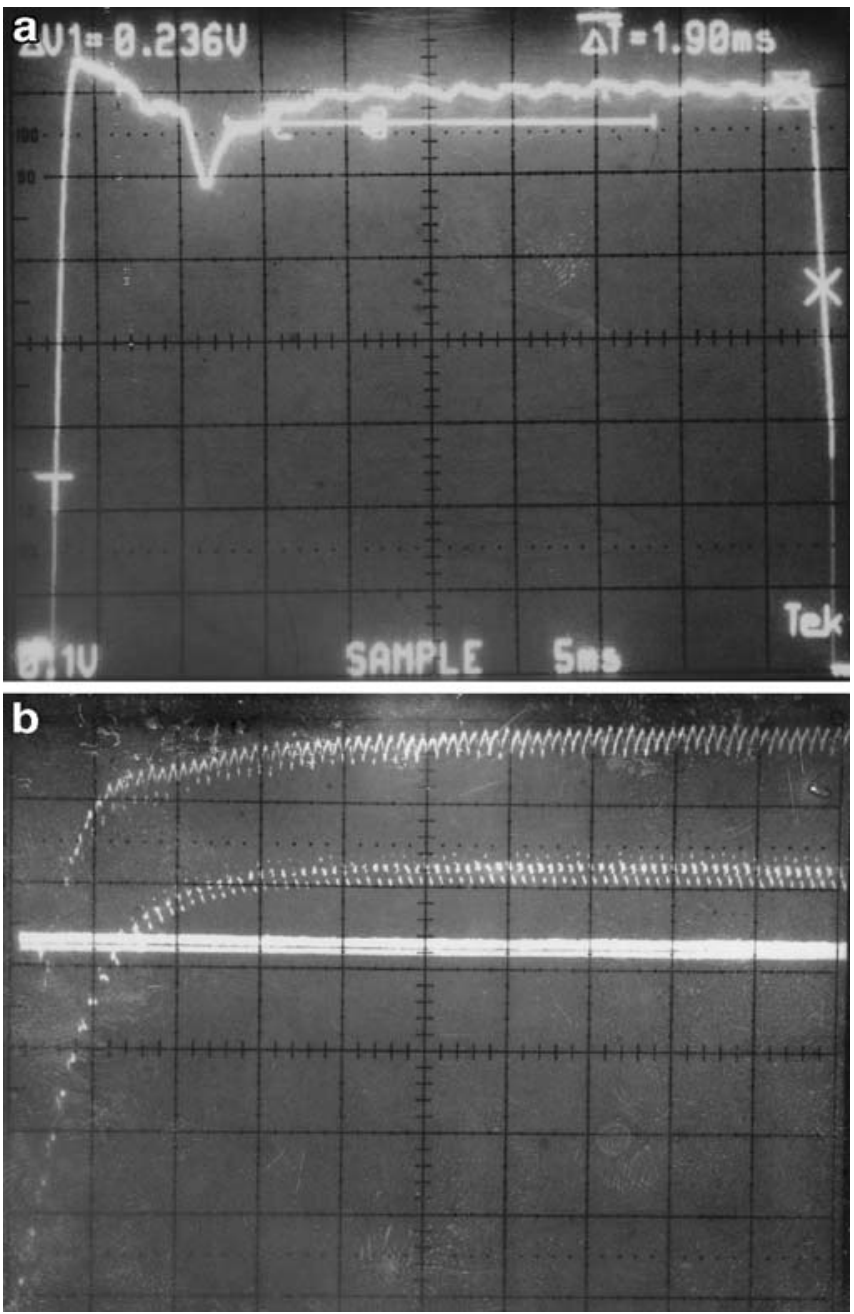

Fig. 12 Illustrates kVp waveforms. a $110 \mathrm{kVp}, 400 \mathrm{~mA}, 45 \mathrm{~ms}$ $(10 \mathrm{kV} / \mathrm{div}, 5 \mathrm{~ms} / \mathrm{div})$. The high-tension tank had to be replaced to correct the $10-\mathrm{kVp}$ drop. b High voltage $(10 \mathrm{kV} / \mathrm{div}, 5 \mathrm{~ms} / \mathrm{div}$, top trace) and tube current $(50 \mathrm{~mA} /$ div, bottom trace $)$. Calibrated $\mathrm{kVp}$ and $\mathrm{mA}$ values were obtained after $25 \mathrm{~ms}$ because of extended rise time for both. A noninvasive $\mathrm{kVp}$ meter with only a digital display could fail to indicate the malfunctions in both $\mathbf{a}$ and $\mathbf{b}$. Reprinted with permission of the RSNA [41]

maximum expected measured performance level is larger because of the errors introduced by the test equipment as defined by Eq. (1)

$\sigma_{\text {total }}^{2}=\sigma_{\text {ie }}^{2}+\sigma_{\text {te }}^{2}$

where $\sigma_{i e}$ is the maximum expected error caused by the fluoroscopic equipment, $\sigma_{\mathrm{te}}$ is the maximum expected error because of test equipment, and $\sigma_{\text {total }}$ is the maximum expected measured performance level of the imaging device.

The performance of imaging equipment has significantly improved over the last 30 years. Electronic advances of the imaging equipment's hardware deserve part of the credit. Imaging science is also better understood today, which leads to better design of the imaging equipment. Imaging
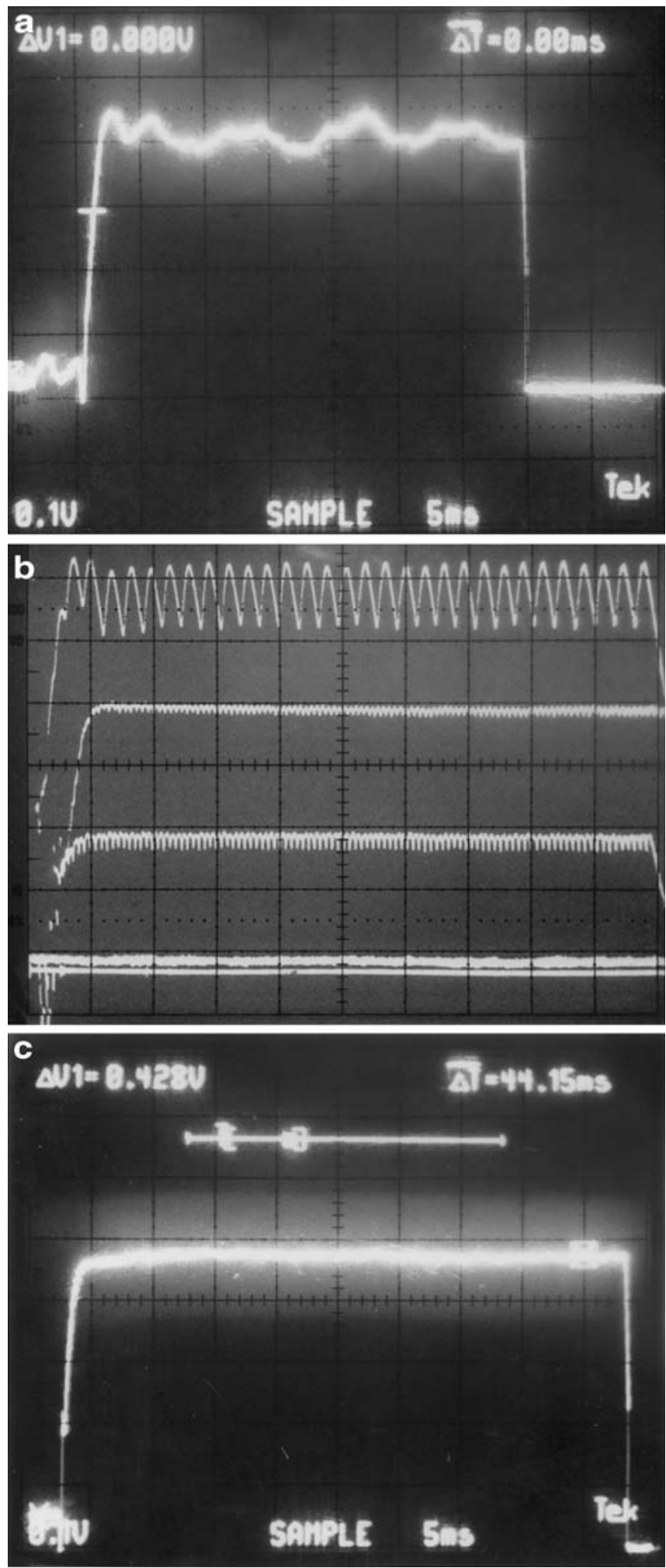

Fig. 13 High-voltage waveforms from different generators. a $81 \mathrm{kV}$ exposure, three-phase, 12-pulse system, new in late $1970 \mathrm{~s}(10 \mathrm{kV} /$ div, $5 \mathrm{~ms} / \mathrm{div}$ ) with wide variation of high voltage. b 90,110 , and $130 \mathrm{kV}$, mid-frequency new in 1987 (10 kV/div, $5 \mathrm{~ms} / \mathrm{div})$. c $90 \mathrm{kV}$, mid-frequency new in 1996 (10 kV/div, $5 \mathrm{~ms} / \mathrm{div})$. Reprinted with permission of the RSNA [41] 
equipment that is software- or firmware-controlled and calibrated eliminates many of the installation errors caused by the human mistakes previously found during acceptance testing. The high-voltage waveforms illustrated in Fig. 13 demonstrate these improvements. Ripple is eliminated, rise and decay times are short, the high-voltage value is constant from the beginning to end of the exposure, and the actual measured high voltage matches the nominal value selected on the control of the X-ray generator.

The dramatic improvement in performance of quality imaging equipment begs the question, "Is acceptance testing of imaging equipment still necessary?" The answer is "yes". Fewer installation errors and equipment hardware failures are identified during acceptance testing. However, a smaller fraction of these errors are identified and eliminated by the installer because the installer performs much less testing of the equipment because of his/her streamlined, software-controlled setup of the equipment during installation. Acceptance testing is also important as a complete functional test of all modes of the operation of the equipment. All configurations of anatomical programming must be tested prior to first patient use to ensure that the machine is performing as expected, especially if the anatomical programming is changed at installation to better meet the unique imaging challenges of pediatrics.

\section{Staff education and training}

Initial and continuing education of all operators of the equipment and associated staff present in the procedure room during examinations is required to ensure highquality imaging at reduced radiation doses to both patients and operators. All staff, physicians, technologists, nurses, anesthesiologists, etc., must receive appropriate generic instruction on basic imaging principles, quality control, radiation protection, and required equipment care before receiving specific instructions for a new unit. The imaging medical physicist should provide generic instruction on these topics during regularly scheduled in-service presentations prior to completion of acceptance testing. Prior to applications training during initial clinical use of the installed equipment, some operators and/or technologists might benefit from visiting another clinical site at which the vendor has established a training relationship. Vendors also might periodically provide training programs for technologists or physicians at the vendor's headquarters.

The vendor's applications specialist who visits the site after acceptance testing is completed is trained to explain the unique design, operational features, and function of each control of the installed imager. Lead operators should image phantoms and receive answers to their questions prior to imaging the first patients. A follow-up visit by the vendor's trainer might be necessary weeks later to further develop the experience and skills of the operators.

\section{Routine performance testing}

Routine performance testing, usually less rigorous than acceptance testing but typically performed with the same test equipment, should be performed throughout the equipment's lifetime to verify continued performance similar to the original documented performance levels. If substandard performance is identified, further, more rigorous testing might be required, followed by adjustment or repair of the radiographic equipment. Follow-up routine performance testing should always be performed after completion of any major repairs or after performance of any requested maintenance or adjustments.

\section{Equipment maintenance and repair}

The buyer should implement an effective periodic maintenance program in addition to an efficient repair program. Periodic maintenance provides scheduled time to inspect equipment and eliminate problems prior to their negative impact on patient care. Repair parts can be ordered and installed at scheduled times. Fluoroscopic equipment receiving periodic maintenance should be out of service for less time than imaging units without periodic maintenance [24, 42-44]. The extra expense of extended service coverage for the equipment is cost-effective if the unit must function over extended hours because of the nature of the clinical practice and if availability of emergency backup services is limited for patients in the community.

The best type of service program for a fluoroscope depends on the amount of self-insuring (risk) that is acceptable to the owner balanced against the amount of service dollars saved [15, 24, 45]. Service contracts with the original equipment manufacturer (OEM) fix costs and minimize financial risks, are the most costly $(8-10 \%$ of equipment purchase price), might provide a limited periodic maintenance program, and seldom provide imaging physics support. Third-party service organizations have the potential to save money and provide the same quality of service as the OEM, but these companies might have limited knowledge or experience working with the equipment or limited access to repair parts.

In recent years, the large imaging companies have developed programs to provide service for all equipment in either the imaging department or the entire institution. The signed imaging company provides OEM service support for its manufactured imaging equipment but third-party service support on all of its competitors' imaging equipment. If an institution owns a mix of imaging equipment from different vendors, the quality of service support across vendor lines will probably not be uniform.

Service agreements with third-party insurance companies are designed to save costs, but the buyer should be wary. The cost of quality periodic maintenance and repairs constantly competes with the insurance company's desire to maximize their profits. Disputes between the insurance company and customer concerning the quality or necessity of a repair must be settled prior to completion of the repair. 
These disputes can result in delays in making timely repairs, which negatively impacts patient revenues.

The customer might elect to service the imaging equipment with properly trained and equipped employees of its own in-house service organization. This requires recruiting qualified personnel, ongoing training, maintaining spare parts inventories, obtaining appropriate tools and test equipment, providing work space, and the assumption of considerable risk. The benefits include complete control of a service program tailored to the unique needs of the department, more efficient response to failed equipment, comprehensive periodic maintenance programs, and up to $30 \%$ savings with respect to full-service contracts from the OEM [24, 43]. In-house service programs can save money if staffed and managed properly. This success is only achieved, however, after the customer commits to a sizeable, proper initial investment in the program.

\section{Record-keeping}

Careful documentation of the imaging equipment's performance is an integral part of a comprehensive quality improvement program [46]. Computer spreadsheet templates specific to each type of equipment record and analyze all data collected during acceptance testing. The actual test equipment and test methods are also recorded with the performance data. Computer algorithms facilitate the comparison of the current performance levels with the original baseline performance data - a comparison that quickly allows appropriate analysis of current measured performance data.

\section{Conclusion}

This article describes a comprehensive quality improvement program for fluoroscopic imaging equipment that should begin when the need for the equipment is first identified by the facility. The imaging physicist of the facility or someone else on behalf of the customer must function as the project manager and interpreter to ensure good communication between the variety of clinical stakeholders and the numerous architects, engineers, and other building/construction professionals during facility planning and construction. After installation and acceptance-testing of the equipment is complete, a comprehensive, ongoing quality improvement program is required to maintain equipment performance at optimum levels throughout its lifetime. More information on all aspects of an ongoing comprehensive quality improvement program for interventional equipment is available elsewhere [19].

The technical advances in state-of-the-art imaging equipment do not eliminate the need to rigorously acceptance-test new equipment. Fewer installation errors and equipment hardware failures exist today, but a smaller fraction of these errors are identified by the installer because of his/her streamlined software-controlled setup of the equipment. Acceptance testing can provide a more complete functional test of the numerous operational modes of state-of-the-art equipment. All configurations of anatomical programming must be tested prior to first patient use to ensure that the machine is performing as expected, especially after the anatomical programming is changed to address the unique challenges of pediatric imaging.

\section{References}

1. Hendee WR, Spitzer VM, Banjavic RL, et al (1985) Identification of clinical needs (roentgenography). In: Hendee WR (ed) The selection and performance evaluation of radiologic equipment. Williams and Wilkins, Baltimore, pp 4-33

2. Busser JH (1975) A purchase guideline for x-ray equipment philosophy, approach, and genesis. Proc SPIE 70:251-262

3. Christie J (1975) Performance specifications from the radiologist's perspective. Proc SPIE 70:242-243

4. Vyborny CJ (1994) Image quality: the radiologist's perspective. In: Siebert JA, Barnes GT, Gould RG (eds) Specification, acceptance testing and quality control of diagnostic $\mathrm{x}$-ray imaging equipment. AAPM monograph no. 20, AAPM 1991 Summer School Proceedings. American Institute of Physics, New York, pp 145-172

5. McMullen HD (1975) Technique for the development of bid specifications and equipment purchasing. Proc SPIE 70:249-250

6. Finster CE, Hendee WR (1985) Justifying the purchase of radiologic equipment. In: Hendee WR (ed) The selection and performance evaluation of radiologic equipment. Williams and Wilkins, Baltimore, pp 34-39

7. Strauss KJ (2002) Interventional equipment acquisition process: cradle to grave. In: Balter S, Chan RC, Shope TB (eds) Intravascular brachytherapy fluoroscopically guided interventions. Medical Physics Publishing, Madison, pp 797-848

8. Barnes GT (1994) Specification of diagnostic x-ray imaging equipment and the bid process. In: Siebert JA, Barnes GT, Gould RG (eds) Specification, acceptance testing and quality control of diagnostic $x$-ray imaging equipment. AAPM monograph no. 20. AAPM 1991 Summer School Proceedings. American Institute of Physics, New York, pp 11-32

9. Gray JE, Morin RL (1989) Purchasing medical imaging equipment. Radiology 171:9-16

10. Hendee WR, Rossi RP (1976) The exchange of information between the purchaser and supplier of radiologic imaging equipment. Proc SPIE 96:385-388

11. Hendee WR, Rossi RP (1976) Performance specifications for diagnostic x-ray equipment. Radiology 120:409-412

12. Hendee WR, Rossi RP, Spitzer VM, et al (1985) Preparation of performance specifications. In: Hendee WR (ed) The selection and performance evaluation of radiologic equipment. Williams and Wilkins, Baltimore, pp 40-84

13. Joseph PM (1975) The role of the hospital physicists in performance specifications. Proc SPIE 70:244-247

14. Stone T (1977) Equipment acquisition procedures. Proc SPIE 127:167-171

15. Strauss KJ, Rossi RP (1994) Specification, acceptance testing, and quality control of mammography imaging equipment. In: Haus AG, Yaffe MJ (eds) Syllabus: a categorical course in physics - technical aspects of breast imaging. Radiological Society of North America (RSNA), Oak Brook, pp 219-246

16. Roeck WW (1994) X-ray room preparation: layout and design considerations. In: Siebeert JA, Barnes GT, Gould RG (eds) Specification, acceptance testing and quality control of diagnostic X-ray imaging equipment. AAPM monograph no. 20, AAPM 1991 Summer School Proceedings. American Institute of Physics, New York, pp 965-992

17. Rossi RP, Hendee WR (1980) Facility planning and preparation. In: Hendee WR (ed) The selection and performance evaluation of radiologic equipment. Williams and Wilkins, Baltimore, pp 88-97 
18. Strauss KJ, Damiano M, Rulli R (1996) Electrical and mechanical hazards. In: Ansel G, Bettman MA, Kaufman JA (eds) Complications in diagnostic imaging and interventional radiology. Blackwell Science, Cambridge, pp 143-164

19. National Council on Radiation Protection and Measurements (2004) Report no. 147. Structural shielding design for medical X-ray imaging facilities. National Council on Radiation Protection and Measurements, Bethesda, pp 1-115

20. Bushong SC (1994) Specification/acceptance testing of radiation shielding. In: Siebert JA, Barnes GT, Gould RG (eds) Specification, acceptance testing and quality control of diagnostic x-ray imaging equipment. AAPM monograph no. 20. AAPM 1991 Summer School Proceedings. American Institute of Physics, New York, pp 993-1015

21. Strauss KJ (1982) X-ray room barrier acceptance testing. In: Lin P-JP, Kriz RJ, Rauch PL, et al (eds) Acceptance testing of radiological imaging equipment. AAPM Symposium Proceedings No. 1. American Institute of Physics, New York, pp 255-274

22. Cleveland JR (1976) Will the real clinical performance requirements for X-ray diagnostic systems please stand up? Proc SPIE 96:400-405

23. Kok PW (1975) Performance specifications from the manufacturer's point of view. Proc SPIE 70:248

24. Rossi RP (1989) Equipment maintenance: a cost comparison of vendor and in-house service. Radiol Manag 11:28-34

25. Scheid CC (1976) Acceptance testing - is it worth the effort? Proc SPIE 96:392-396

26. Stanhope GP (1976) Purchase specifications - a manufacturer's viewpoint. Proc SPIE 96:397-399

27. Bhatnagar JP, Rao GU (1970) Kilovoltage calibration of diagnostic roentgen ray generators. Acta Radiol Ther Phys Biol 9:555-566

28. Harrison RM, Forster E (1984) Performance characteristics of $\mathrm{X}$-ray tubes and generators. Radiography 50:245-248

29. Hendee WR (1985) Acceptance testing. In: Hendee WR (ed) The selection and performance evaluation of radiologic equipment. Williams and Wilkins, Baltimore, pp 98-162

30. Kanamori H (1965) Analysis of high-voltage wave forms in $\mathrm{x}-$ ray units: abnormal voltages. J Franklin Inst 279:246-253

31. Kanamori H (1965) Analysis of high-voltage wave forms in $x-$ ray units: I. Single phase. J Franklin Inst 279:147-159

32. Kanamori H (1965) Analysis of high-voltage wave forms in $x-$ ray units: III. Three phase. J Franklin Inst 279:347-359

33. Randall MG, Horn B (1977) Systems approach to acceptance testing diagnostic x-ray equipment. Proc SPIE 127:158-166

34. Rauch PL (1977) Performance evaluation of the falling load techniques. Proc SPIE 127:145-151
35. Rauch PL (1982) Performance characteristics of diagnostic xray generators. In: Lin P-JP, Kriz RJ, Rauch PL, et al (eds) Acceptance testing of radiological imaging equipment. AAPM Symposium Proceedings No. 1. American Institute of Physics, New York, pp 126-156

36. Rauch PL, Block R (1976) Acceptance testing experience with fourteen new installations. Proc SPIE 196:12-18

37. Rossi RP (1982) Acceptance testing of radiographic x-ray generators. In: Lin P-JP, Kriz RJ, Rauch PL, et al (eds) Acceptance testing of radiological imaging equipment. AAPM Symposium Proceedings No. 1. American Institute of Physics, New York, pp 110-125

38. Rossi RP (1985) Acceptance testing (roentgenography). In: Hendee WR (ed) The selection and performance evaluation of radiologic equipment. Williams and Wilkins, Baltimore, pp 98-130

39. Rossi RP, Lin P-JP, Rauch PL, et al (1985) Performance specifications and acceptance testing for $\mathrm{X}$-ray generators and automatic exposure control devices. AAPM Report No. 14 American Institute of Physics, New York, pp 1-96

40. Starchman DE, Johnson RG, Hykes DL, et al (1976) Role of $\mathrm{kVp}$ accuracy of diagnostic $\mathrm{x}$-ray units and other performance parameters in quality assurance. Proc SPIE 96:31-36

41. Strauss KJ (1996) Radiographic equipment and components technology overview and quality improvement. In: Gould RG, Boone JM (eds) Syllabus: a categorical course in physicstechnology update and quality improvement of diagnostic x-ray imaging equipment. Radiological Society of North America (RSNA), Oak Brook, pp 21-48

42. Barnes GT (1980) When is in-house service cost effective? Proc SPIE 233:286-290

43. Brown WJ, McDanal WL (1980) An alternate to vendor supplied service. Proc SPIE 233:286-290

44. Wagner AJ, Barnes GT, Wu XZ (1991) Assessing fluoroscopic contrast resolution: a practical and quantitative test tool. Med Phys 18:894-899

45. Rossi RP, Owen DA (1985) Preventive maintenance and service. In: Hendee WR (ed) The selection and performance evaluation of radiologic equipment. Williams and Wilkins, Baltimore, pp 209-220

46. Rossi RP (1994) QC program documentation: the University of Colorado approach. In: Siebert JA, Barnes GT, Gould RG (eds) Specification, acceptance testing and quality control of diagnostic x-ray imaging equipment. AAPM monograph no. 20, AAPM 1991 Summer School Proceedings. American Institute of Physics, New York, pp 1075-1112 